\title{
Deposição de nutrientes na carcaça de girinos de rã-touro
}

\author{
Cleber Fernando Menegasso Mansano(1), Marta Verardino De Stéfani(1), \\ Marcelo Maia Pereira ${ }^{(1)}$ e Beatrice Ingrid Macente $^{(2)}$
}

\begin{abstract}
(1)Universidade Estadual Paulista (Unesp), Centro de Aquicultura, Via de Acesso Prof. Paulo Donato Castellane, s/no, CEP 14884-900 Jaboticabal, SP. E-mail: clebermansano@hotmail.com, martavs@fcav.unesp.br, mmaiap2001@yahoo.com.br(2)Unesp, Faculdade de Ciências Agrárias e Veterinárias, Departamento de Obstetrícia e Reprodução Animal, Via de Acesso Prof. Paulo Donato Castellane, s/no, CEP 14884-900 Jaboticabal, SP. E-mail: beatrice.vetuel@yahoo.com.br
\end{abstract}

Resumo - O objetivo deste trabalho foi determinar a deposição de nutrientes na carcaça de girinos de rã-touro (Lithobates catesbeianus) por meio de modelo não linear. Foram utilizados 2.700 girinos com peso médio inicial de 0,039 g. Ração comercial farelada com $55 \%$ de proteína bruta foi fornecida ad libitum. Os animais foram pesados e avaliados a cada dez dias para análise dos conteúdos de proteína bruta, extrato etéreo, água e sais minerais. Os parâmetros do modelo Gompertz foram estimados pelo método de Gauss-Newton modificado, e as taxas de deposição (g por dia) em função do tempo foram calculadas por meio da derivada da equação. Os valores encontrados para os parâmetros da equação de Gompertz, para descrever a deposição dos nutrientes na carcaça de girinos, apresentaram interpretação biológica. A taxa máxima ( $\left.\mathrm{t}^{*}\right)$ de deposição foi observada aos 36,2331 dias para proteína, aos 37,1420 dias para água, aos 35,2971 dias para sais minerais, e aos 41,3547 dias para gordura. O consumo de nutrientes da dieta é maior do que a taxa de deposição na carcaça dos girinos.

Termos para indexação: Lithobates catesbeianus, composição corporal, modelo de Gompertz, nutrição.

\section{Nutrient deposition in bullfrog tadpole carcass}

\begin{abstract}
The objective of this work was to determine nutrient deposition on the carcass of bullfrog (Lithobates catesbeianus) tadpoles using a nonlinear model. A total of 2,700 tadpoles with an average weight of $0.039 \mathrm{~g}$ were used. Commercial ground feed containing $55 \%$ crude protein was offered ad libitum. The animals were weighed and evaluated every ten days for analysis of crude protein, ether extract, water, and mineral salt contents. The parameters of the Gompertz model were estimated by the modified Gauss-Newton method, and the deposition rates (g per day) over time were calculated by the resulting equation. The values found for the parameters of the Gompertz equation, used to describe nutrient deposition on tadpole carcass, showed biological interpretation. Maximum deposition rate $\left(t^{*}\right)$ was observed on the $36.2331^{\text {th }}$ day for protein, on the $37.1420^{\text {th }}$ day for water, on the $35.2971^{\text {th }}$ day for mineral salt, and on the $41.3547^{\text {th }}$ day for fat. Nutrient intake from the diet is higher than the deposition rate on the tadpole carcass.
\end{abstract}

Index terms: Lithobates catesbeianus, corporal composition, Gompertz model, nutrition.

\section{Introdução}

O aumento da demanda de proteína de origem animal pela aquicultura tem ocasionado elevação dos preços desta matéria prima e, consequentemente, das rações. Com isso, torna-se necessário o desenvolvimento de novas pesquisas para o aprimoramento da ranicultura, para diminuir os custos com a produção nas diferentes etapas do seu desenvolvimento.

A rã-touro (Lithobates catesbeianus) é um anfíbio anuro que apresenta um ciclo de vida complexo, com duas fases bem distintas - na fase inicial, o animal é aquático e, na segunda, é terrestre (Wilbur, 1980). Para um bom funcionamento do ranário, a fase inicial, ou girinagem, é de extrema importância para a produção de imagos saudáveis em condições ideais para se realizar a recria (Seixas Filho et al., 2011, 2012).

A alimentação adequada é ponto fundamental na criação de animais, já que, muitas vezes, a ocorrência de mortalidade ou o desenvolvimento desordenado é sinal clássico de possíveis desordens nutricionais (Hipolito et al., 2004, 2007).

A maior parte dos estudos para o aprimoramento da alimentação e da nutrição têm focado na necessidade de proteína e energia bruta (Barbosa et al., 2005; Seixas Filho et al., 2010). Da mesma forma, a digestibilidade da proteína e da energia de alguns alimentos utilizados em rações de girinos tem sido avaliada (Albinati et al., 2000; Secco et al., 2005). Entretanto, a exigência nutricional dos girinos ainda não foi determinada, o 
que provavelmente resulta em administrações de dietas de outras espécies com necessidades nutricionais diferentes, como as de peixes carnívoros (Seixas Filho et al., 2008).

Portanto, são necessários trabalhos que permitam elaborar modelos de crescimento para o estabelecimento de programas de nutrição e melhoramento genético na ranicultura (Santos et al., 2007; Marcato et al., 2010).

Modelos matemáticos não lineares apresentam alguns parâmetros que mostram as características de crescimento dos indivíduos por meio do perfil das respostas ao longo do tempo. Isso pode ajudar a identificar os animais de maior peso em menor idade, e a obter a variância entre e dentre indivíduos, o que é de grande interesse nas avaliações genéticas (Marcato et al., 2010; Silva et al., 2011).

Já foram descritos modelos não lineares para vários animais domésticos, como frango (Marcato et al., 2008), ovinos (Sarmento et al., 2006), vacas de corte (Silva et al., 2011), tilápia-do-nilo (Santos et al., 2007), rã-touro na fase pós-metamórfica (Rodrigues et al., 2007) e girinos de rã-touro (Mansano et al., 2012). Os resultados obtidos são indicativos de que o crescimento em peso destas espécies se ajustou para estes modelos com qualidade estatística.

O objetivo deste trabalho foi determinar a deposição dos nutrientes na carcaça de girinos de rã-touro por meio de modelo não linear.

\section{Material e Métodos}

O experimento foi conduzido na Universidade Estadual Paulista, Centro de Aquicultura, Ranário Experimental, Jaboticabal, SP, durante 63 dias, de janeiro a março de 2011. Foram utilizados 2.700 girinos de rã-touro com peso médio inicial de $0,039 \mathrm{~g}$, estágio 25 de Gosner (1960), os quais foram distribuídos em seis (repetições) caixas com capacidade de $500 \mathrm{~L}$.

Para alimentação dos animais, foi utilizada ração comercial farelada (Tabela 1), fornecida ad libitum. Toda a ração ofertada foi pesada em balança digital, com $0,01 \mathrm{~g}$ de precisão, para cálculo de consumo.

A água das caixas foi renovada, em sua totalidade, a cada 24 horas, e as temperaturas máxima e mínima do ambiente e da água das caixas foram medidas diariamente por meio de termômetro digital para maxíma e mínima (Incoterm, São Paulo, SP. Os seguintes valores foram aferidos semanalmente: oxigênio dissolvido, com medidor de oxigênio, modelo Pro 20 (YSI Incorporated, Yellow Springs, $\mathrm{OH}, \mathrm{EUA})$; condutividade, com condutivímetro de bolso, modelo CD-203 (PHTEK, Curitiba, PR); e pH, com pHmetro de bolso, modelo pH-100 (PHTEK, Curitiba, PR).

Os dados de peso vivo foram coletados aos 0,12 , 20, 29, 42, 54 e 63 dias por amostragem; ao longo de todo o período experimental, 40 animais de cada caixa foram pesados em balança digital com precisão de $0,01 \mathrm{~g}$. O último dia de coleta foi determinado pelo início do clímax de metamorfose dos animais, estágio 42 (Gosner, 1960), quando os girinos param de se alimentar.

Para a análise dos nutrientes na carcaça, os girinos foram mantidos em jejum durante 24 horas, insensibilizados em gelo e congelados. As carcaças, após congeladas, foram moídas em processador de alimentos para obtenção de amostras homogêneas, as quais foram acondicionadas em placas de Petri, de plástico descartável, e, posteriormente, liofilizadas a $50^{\circ} \mathrm{C}$ em equipamento Thermo VLP200 (Thermo Fisher Scientific Inc., Waltham, MA, EUA), para obtenção da matéria pré-seca. Em seguida, as carcaças foram novamente moídas em moinho de bola e encaminhadas ao laboratório para análises de proteína, extrato etéreo, matéria seca e sais minerais.

Tabela 1. Nível de garantia do fabricante (NGF) e composição centesimal analisada (CCA) da dieta comercial.

\begin{tabular}{lcc}
\hline Composição(1) $^{(1)}$ & NGF & CCA \\
\hline Umidade (\%) & 10,0 (máx.) & - \\
Proteína bruta (\%) & 55,0 (mín.) & 57,53 \\
Extrato etéreo (\%) & 7,0 (mín.) & 8,43 \\
Energia bruta (kcal cal ${ }^{-1}$ ) & - & 5003,08 \\
Fibra bruta (\%) & 2,8 (máx.) & - \\
Minerais (\%) & 17,0 (máx.) & 10,92 \\
Ca (\%) & 4,2 (máx.) & - \\
Fósforo (\%) & 1,5 (mín.) & - \\
\hline
\end{tabular}

${ }^{(1)}$ Composição básica da ração: milho integral moído, farelo de soja, farelo de glúten de milho 60, farinha de carne e ossos, farinha de penas hidrolisadas, farinha de sangue, gordura vegetal estabilizada, cloreto de sódio (sal comum), cloreto de colina, calcário calcítico. Eventuais substitutivos: sorgo integral moído, quirera de arroz, farelo de milho, farelo de glúten de milho, farelo de trigo, farelo de arroz, levedura seca de cana-de-açúcar. Premix: vitamina A (mín.), 35.000 U.I.; vitamina D3 (mín.), 2.000 U.I.; vitamina E (mín.), 120 U.I.; vitamina K3 (mín.), $800 \mathrm{mg}$; ácido fólico (mín.), 10 mg; biotina (mín.), 10 mg; tiamina (B1) (mín.), $25 \mathrm{mg}$; riboflavina (B2) (mín.), 35 mg; piridoxina (B6) (mín.), 40 mg; vitamina B12 (mín.), 100 mcg; niacina (mín.), 350 mg; ácido pantotênico (mín.), 150 mg; colina (mín.), $2.500 \mathrm{mg}$; cobre (mín.), $25 \mathrm{mg}$; ferro (mín.), $150 \mathrm{mg}$; manganês (mín.), 75 mg; selênio (mín.), 1 mg; zinco (mín.), 140 mg; mananoligossacarídeo (mín.), $60 \mathrm{mg}$. 
Todos os procedimentos descritos foram aprovados pela Comissão de Ética no Uso de Animais (Ceua), da Faculdade de Ciências Agrárias e Veterinárias, da Universidade Estadual Paulista, protocolo 025000/10, e estão de acordo com os princípios éticos na experimentação animal elaborados pelo Colégio Brasileiro de Experimentação Animal (Cobea).

A proteína bruta das amostras foi determinada por meio do método de Dumas, em aparelho Leco 528 LC (Etheridge et al., 1998). Para a análise do extrato etéreo, foi realizada a extração com éter de petróleo em aparelho Soxhlet (Sigma-Aldrich, St. Louis, MO, EUA). Os sais minerais foram determinados em mufla, a $550^{\circ} \mathrm{C}$, por incineração. A matéria seca foi obtida em estufa a $105^{\circ} \mathrm{C}$ por 12 horas. As metodologias utilizadas para as análises estão descritas em Silva \& Queiroz (2002).

O modelo utilizado para descrever a curva de crescimento foi o de Gompertz:

$$
\mathrm{Pt}=\mathrm{Pm} \times \exp \left\{-\exp \left[-\mathrm{b} \times\left(\mathrm{t}-\mathrm{t}^{*}\right)\right]\right\},
$$

em que: Pt é o peso dos nutrientes ( $\mathrm{g}$ ) do animal ao tempo t, expresso em função do Pm; Pm é o peso dos nutrientes (g) à maturidade do animal; b é a taxa de maturidade (por dia); e t* é o tempo (dias) em que a taxa de deposição é máxima. Com base na equação estimada, calcularam-se as taxas de deposição (g por dia) em função do tempo (t), por meio da derivada das equações descritas por Gompertz (1825) e adotadas por Mansano et al. (2012), para descrever o crescimento de girinos de rã-touro. Os parâmetros dos modelos foram estimados pelo método de Gauss Newton modificado, por meio de regressão não linear, com uso do procedimento NLIN do SAS.

\section{Resultados e Discussão}

As temperaturas médias máxima e mínima do ambiente foram $31,9 \pm 1,86$ e $25,5 \pm 1,27^{\circ} \mathrm{C}$, respectivamente, e da água das caixas foram $31,4 \pm 1,14$ e $25,5 \pm 1,43^{\circ} \mathrm{C}$, respectivamente. Os valores médios de oxigênio dissolvido, $\mathrm{pH}$ e condutividade elétrica da água foram 4,22 $\pm 1,06 \mathrm{mg} \mathrm{L}^{-1}, 7,47 \pm 0,38$ e 202,48 $\pm 11,71$ $\mu \mathrm{S} \mathrm{cm}^{-1}$, respectivamente. No geral, os parâmetros hídricos apresentaram-se relativamente constantes em todas as caixas e de acordo com o recomendado para a espécie (Bambozzi et al., 2004; Hayashi et al., 2004; Arauco et al., 2007).
As curvas de deposição dos nutrientes para girinos de rã-touro alimentados com uma dieta comercial contendo alto teor de proteína foram descritas (Figura 1), e as estimativas dos parâmetros da equação de Gompertz apresentaram interpretação biológica (Tabela 2).

As curvas de deposição dos quatro nutrientes apresentaram formato sigmoidal e coerência da interpretação biológica do parâmetro $\operatorname{Pm}(\mathrm{g})$, que representou o peso do nutriente à maturidade. Esse resultado corrobora o obtido por Mansano et al. (2012), que avaliaram diferentes modelos não lineares e elegeram o modelo de Gompertz como sendo o melhor para descrever o crescimento de girinos de rã-touro desde o estágio 25 de Gosner (1960) até o clímax de metamorfose. O padrão da curva de crescimento de girinos é consideravelmente diferente do padrão de animais pós-metamorfose. No primeiro caso, a taxa de crescimento é rápida e a função exponencial do modelo de Gompertz se encaixa bem aos dados. As variáveis paramétricas do modelo podem ser geradas por vários processos biológicos, como fornecimento, distribuição e acesso do animal ao alimento, bem como variações na qualidade da comida, nas partículas ou na heterogeneidade dos animais, o que ocasiona competições e interfere na curva e na deposição de nutrientes (Hota, 1994).

Adeposição e o acúmulo de proteínas, principalmente na cauda do girino, são necessários durante o clímax de metamorfose, quando ocorre apoptose da cauda e relocação de proteína para transformação da estrutura do animal de vida aquática para vida terrestre (Ishizuya-Oka et al., 2010). O consumo de proteína da dieta pelos girinos de rã-touro foi superior à sua deposição na carcaça (Tabela 3). Isso provavelmente decorreu da baixa qualidade da proteína dos ingredientes da dieta comercial, que não foi aproveitada pelos animais e, portanto, é inadequada aos girinos de rã-touro (Seixas Filho et al., 2010). Além disso, o excesso de proteína pode ocasionar problemas renais e hepáticos, pois aumenta a quantidade de nitrogênio eliminado pelos rins, o que o sobrecarrega e pode comprometer o seu funcionamento (Seixas Filho et al., 2008).

No trigésimo sexto dia do período experimental, a taxa de deposição proteica ( $\mathrm{t}^{*}$ ) foi máxima (Tabela 2). Em seguida, os girinos apresentaram redução mais acentuada na taxa de deposição deste componente

Pesq. agropec. bras., Brasília, v.48, n.8, p.885-891, ago. 2013 DOI: $10.1590 / \mathrm{S} 0100-204 \mathrm{X} 2013000800011$ 
corporal (Tabela 3). Observou-se que a quantidade de proteína depositada na carcaça dos girinos foi maior do que a de gordura, o que pode ser atribuído ao requerimento maior deste nutriente pelos girinos.
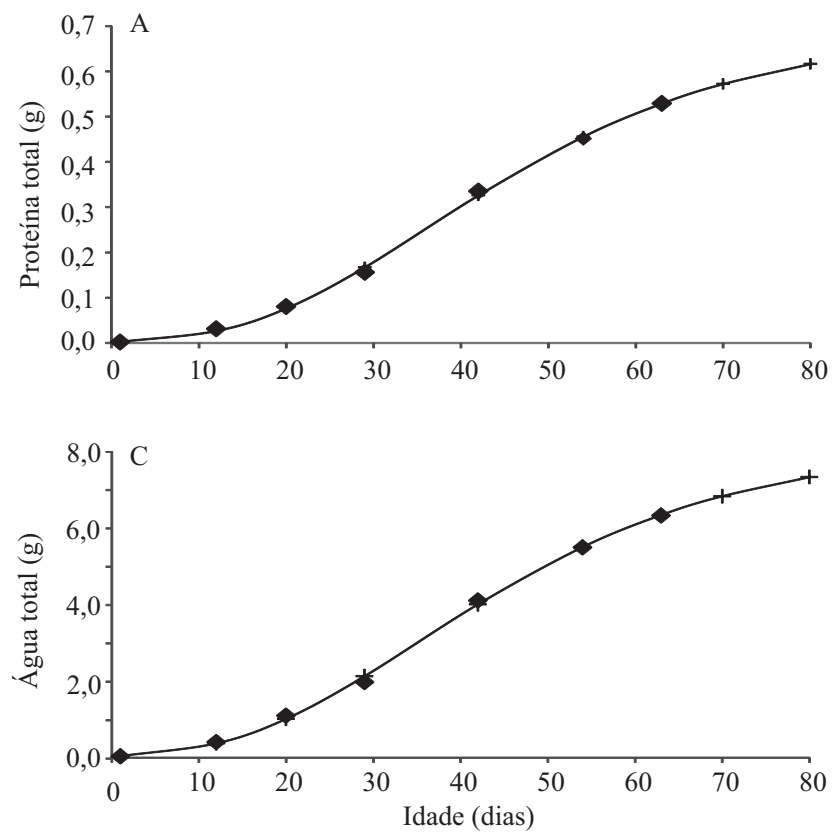

Nos girinos, o tecido adiposo pode ocorrer como depósitos individualizados, como na região visceral, na forma de corpo adiposo, ou distribuído de forma menos difusa em músculos, fígado, pele, rins, pulmões,

\section{$\longrightarrow$ Gompertz $\diamond$ Observado}

Figura 1. Curvas de deposição dos nutrientes (A, proteína total; B, gordura total; C, água total; e D, sais minerais total), na carcaça de girinos de rã-touro (Lithobates catesbeianus).

Tabela 2. Estimativas dos parâmetros da equação de Gompertz para proteína, gordura, água e sais minerais da carcaça de girinos de rã-touro (Lithobates catesbeianus).

\begin{tabular}{|c|c|c|c|c|c|}
\hline \multirow[t]{2}{*}{ Nutrientes } & \multicolumn{3}{|c|}{ Parâmetros ${ }^{(1)}$} & \multirow[t]{2}{*}{$\mathrm{R}^{2}$} & \multirow[t]{2}{*}{$\mathrm{QMR}^{(2)}$} \\
\hline & $\operatorname{Pm}(\mathrm{g})$ & b (por dia) & $\mathrm{t}^{*}$ (dias) & & \\
\hline Proteína & 0,6931 & 0,0488 & 36,2331 & 0,9727 & 0,0027 \\
\hline Gordura & 0,3569 & 0,0457 & 41,3547 & 0,9653 & 0,0006 \\
\hline Água & 8,7287 & 0,0487 & 37,1420 & 0,9882 & 0,1912 \\
\hline Sais minerais & 0,1230 & 0,0507 & 35,2971 & 0,9776 & 0,2486 \\
\hline
\end{tabular}

${ }^{(1)} \mathrm{Pm}$, peso à maturidade; $b$, taxa de maturidade; $\mathrm{t}^{*}$, tempo de taxa de deposição máxima. ${ }^{(2)} \mathrm{QMR}$, quadrado médio do resíduo.

Tabela 3. Consumo e deposição de nutrientes de acordo com a idade, para girinos de rã-touro (Lithobates catesbeianus).

\begin{tabular}{|c|c|c|c|c|c|c|c|}
\hline \multirow{2}{*}{$\begin{array}{l}\text { Idade } \\
\text { (dias) }\end{array}$} & \multicolumn{2}{|c|}{ Proteína (g por dia) } & \multicolumn{2}{|c|}{ Gordura (g por dia) } & \multirow{2}{*}{$\frac{\text { Água (g por dia) }}{\text { Deposição }^{(1)}}$} & \multicolumn{2}{|c|}{ Sais minerais (g por dia) } \\
\hline & Consumo & Deposição $^{(1)}$ & Consumo & Deposição $^{(1)}$ & & Consumo & Deposição $^{(1)}$ \\
\hline 1 & 0,0058 & 0,00064 & 0,0008 & 0,00016 & 0,0104 & 0,00109 & 0,00005 \\
\hline 12 & 0,0155 & 0,00399 & 0,0023 & 0,00128 & 0,0569 & 0,00294 & 0,00053 \\
\hline 20 & 0,0254 & 0,00796 & 0,0037 & 0,00293 & 0,1069 & 0,00482 & 0,00126 \\
\hline 29 & 0,0414 & 0,01147 & 0,0061 & 0,00485 & 0,1475 & 0,00787 & 0,00201 \\
\hline 42 & 0,0537 & 0,01207 & 0,0079 & 0,00600 & 0,1497 & 0,01019 & 0,00226 \\
\hline 54 & 0,0642 & 0,00947 & 0,0094 & 0,00527 & 0,1155 & 0,01218 & 0,00179 \\
\hline 63 & 0,0608 & 0,00711 & 0,0089 & 0,00424 & 0,0862 & 0,01155 & 0,00134 \\
\hline
\end{tabular}

${ }^{(1)}$ Valores de deposição foram estimados pela derivada da equação de Gompertz. 
ossos e tecido conjuntivo (Wright et al., 2011). A deposição de gordura pode ser de origem genética (Leonhardt et al., 2006); no entanto, outros fatores contribuem para o acúmulo de gordura nos animais, como dieta e condições ambientais (Glencross et al., 2011; Amrkolaie et al., 2012).

Verificou-se, também, que a quantidade de gordura depositada aumentou gradativamente (Tabela 3) em razão do desenvolvimento do corpo adiposo com o crescimento dos girinos, uma vez que, durante a metamorfose, ocorre grande gasto energético (Scott et al., 2007).

A taxa máxima ( $\left.\mathrm{t}^{*}\right)$, ou ponto de inflexão da curva de deposição de gordura na carcaça, ocorreu aos 41,3547 dias e foi mais tardia do que as taxas máximas de proteína (36,2331 dias), água (37,1420 dias) e sais minerais (35,2971 dias) (Tabela 2). É provável que isso tenha sido resultante de uma alteração no metabolismo dos girinos, que passaram a destinar, gradualmente, boa parte da energia ingerida para acúmulo de gordura corporal, compondo a reserva de energia necessária para o início do processo de metamorfose. As taxas máximas ( $\left.\mathrm{t}^{*}\right)$ para deposição de água e proteína foram muito próximas (Tabela 2), pois a deposição de água corporal está intimamente ligada à taxa de deposição de proteína corporal de girinos. Isso indica que o girino retém mais água nesta fase de crescimento, pela maior síntese de proteína.

Também foi observado que a diminuição na deposição de água foi mais acentuada, ou seja, o animal deposita mais gordura do que água na fase final, o que mostra que, quanto maior a quantidade de gordura corporal, menor a deposição de água.

A taxa máxima ( $\left.t^{*}\right)$ de deposição de sais minerais ocorreu antes da dos outros nutrientes (Tabela 2). Isso mostra que, em girinos, o crescimento do tecido ósseo ocorre antes do crescimento do tecido muscular, que, por sua vez, é mais acelerado do que o do tecido adiposo (Gonzales \& Sartori, 2002). Cada indivíduo apresenta uma variação individual e específica do crescimento de cada osso, cujo controle ocorre por meio da físe, ou seja, cada cartilagem de conjugação apresenta taxa específica de desenvolvimento, o que é geralmente genético (Macari et al., 1994).

Os valores dos pesos de consumo e deposição de proteína, gordura, água e sais minerais mostraram que, à medida que os girinos ganharam peso proteico corporal, houve aumento na deposição dos outros nutrientes. Constatou-se, na sequência de deposição de nutrientes no corpo do girino, que a deposição de sais minerais, proteína e água ocorreu em maior quantidade na fase inicial (Tabela 3).

\section{Conclusões}

1. O consumo de nutrientes é maior do que a deposição destes na carcaça dos girinos de rã-touro (Lithobates catesbeianus).

2. O alto teor proteico, de $57,53 \%$ da ração comercial, não é totalmente utilizado pelos girinos de rã-touro.

\section{Agradecimentos}

À Fundação de Amparo à Pesquisa do Estado de São Paulo (Fapesp), pelo apoio financeiro; e ao técnico Marcio Roberto Reche, pelo auxílio na realização do trabalho.

\section{Referências}

ALBINATI, R.C.B.; LIMA, S.L.; TAFURI, M.L.; DONZELE, J.L. Digestibilidade aparente de dois alimentos protéicos e três energéticos para girinos de rã-touro (Rana catesbeiana, Shaw, 1802). Revista Brasileira de Zootecnia, v.29, p.2151-2156, 2000. Suplemento.

AMRKOLAIE, A.K.; YANSARI, A.T.; KHALESI, M.K. Calculation of protein and energy requirements in beluga sturgeon (Huso huso) using a factorial approach. Journal of Animal Physiology and Animal Nutrition, v.96, p.485-494, 2012. DOI: 10.1111/j.1439-0396.2012.01289.x.

ARAUCO, L.R.R.; STÉFANI, M.V. de; NAKAGHI, L.S.O. Efeito do extrato hidroalcoólico de própolis no desempenho e na composição leucocitária do sangue de girinos de rã-touro (Rana catesbeiana). Acta Scientiarum. Animal Sciences, v.29, p.227-234, 2007. DOI: 10.4025/actascianimsci.v29i2.240.

BAMBOZZI, A.C.; SEIXAS FILHO, J.T. de; THOMAZ, L.A.; OSHIRO, L.M.Y. Efeito do fotoperíodo sobre o desenvolvimento de girinos de rã-touro (Rana catesbeiana Shaw, 1802). Revista Brasileira de Zootecnia, v.33, p.1-17, 2004. DOI: 10.1590/ S1516-35982004000100001.

BARBOSA, J.M.; SILVEIRA, A.M.; GOMIDE, C.A. Crescimento heterogêneo de girinos de rã-touro alimentados com diferentes rações. Pesquisa Agropecuária Brasileira, v.40, p.1015-1019, 2005. DOI: 10.1590/S0100-204X2005001000010.

ETHERIDGE, R.D.; PESTI, G.M.; FOSTER, E.H. A comparison of nitrogen values obtained utilizing the Kjeldahl nitrogen and Dumas combustion methodologies (Leco CNS 2000) on samples typical of an animal nutrition analytical laboratory. Animal Feed Science and Technology, v.73, p.21-28, 1998. DOI: 10.1016/ S0377-8401(98)00136-9. 
GLENCROSS, B.; HIEN, T.T.T.; PHUONG, N.T.; CAM TU, T.L. A factorial approach to defining the energy and protein requirements of Tra catfish, Pangasionodon hypothalamus. Aquaculture Nutrition, v.17, p.396-405, 2011. DOI: 10.1111/j.1 365-2095.2010.00774.x.

GOMPERTZ, B. On the nature of the function expressive of the law of human mortality, and on a new mode of determining the value of life contingencies. Philosophical Transactions of the Royal Society, v.115, p.513-585, 1825. DOI: 10.1098/rstl.1825.0026.

GONZALES, E.; SARTORI, J.S. Crescimento e metabolismo muscular. In: MACARI, M.; FURLAN, R.L.; GONZALES, E. (Ed.). Fisiologia aviária aplicada a frangos de corte. Jaboticabal: FUNEP/UNESP, 2002. p.279-298.

GOSNER, K.L. A simplified Table for staging anuran embryos and larvae with notes on identification. Herpetologica, v.16, p.183-190, 1960.

HAYASHI, C.; SOARES, C.M.; GALDIOLI, E.M.; FURUYA, V.R.B.; BOSCOLO, W.R. Desenvolvimento de girinos de rã-touro (Rana catesbeiana, Shaw, 1802) cultivados em diferentes densidades de estocagem em tanque-rede. Revista Brasileira de Zootecnia, v.33, p.14-20, 2004. DOI: 10.1590/S1516-35982004000100003.

HIPOLITO, M.; MARTINS, A.M.C.R.P.F.; BACH, E.E. Aspectos bioquímicos em fígado de rãs-touro (Rana catesbeiana Shaw, 1802) sadias e doentes. Arquivos do Instituto Biológico, v.71, p.147-153, 2004.

HIPOLITO, M.; RIBEIRO FILHO, O.P.; BACH, E.E. Aspecto bioquímico em fígados de Rana catesbeiana (SHAW, 1802) submetidas a diferentes dietas. ConScientiae Saúde, v.6, p.49-56, 2007. DOI: 10.5585/conssaude.v6i1.907.

HOTA, A.K. Growth in amphibians. Gerontology, v.40, p.147-160, 1994. DOI: $10.1159 / 000213584$.

ISHIZUYA-OKA, A.; HASEBE, T.; SHI, Y.-B. Apoptosis in amphibian organs during metamorphosis. Apoptosis, v.15, p.350-364, 2010. DOI: 10.1007/s10495-009-0422-y.

LEONHARDT, J.H.; CAETANO FILHO, M.; FROSSARD, H.; MORENO, A.M. Características morfométricas, rendimento e composição do filé de tilápia do Nilo, Oreochromis niloticus, da linhagem tailandesa, local e do cruzamento de ambas. Semina: Ciências Agrárias, v.27, p.125-132, 2006.

MACARI, M.; FURLAN, R.L.; GONZALES, E. Fisiologia aviária aplicada a frangos de corte. Jaboticabal: FUNEP/UNESP, 1994. $246 \mathrm{p}$.

MANSANO, C.F.M.; DE STÉFANI, M.V.; PEREIRA, M.M.; MACENTE, B.I. Non-linear growth models for bullfrog tadpoles. Ciência e Agrotecnologia, v.36, p.454-462, 2012. DOI: 10.1590/ S1413-70542012000400010.

MARCATO, S.M.; SAKOMURA, N.K.; FERNANDES, J.B.K.; SIQUEIRA, J.C. de; DOURADO, L.R.B.; FREITAS, E.R. Crescimento e deposição de nutrientes nos órgãos de frangos de corte de duas linhagens comerciais. Revista Brasileira de Zootecnia, v.39, p.1082-1091, 2010. DOI: 10.1590/ S1516-35982010000500019.

MARCATO, S.M.; SAKOMURA, N.K.; MUNARI, D.P.; FERNANDES, J.B.K.; KAWAUCHI, Í.M.; BONATO, M.A.
Growth and body nutrient deposition of two broiler commercial genetic lines. Revista Brasileira de Ciência Avícola, v.10, p.117-123, 2008. DOI: 10.1590/S1516-635X2008000200007.

RODRIGUES, M.L.; LIMA, S.L.; MOURA, O.M.; AGOSTINHO, C.A.; SILVA, J.H.V.; CRUZ, G.R.B.; CAMPOS, V.M.; CASALI; A.P.; MENDES, R.R.B.; ALBUQUERQUE, A.G. Curva de crescimento em rã-touro na fase de recria. Archivos de Zootecnia, v.56, p.125-136, 2007.

SANTOS, V.B. dos; FREITAS, R.T.F. de; SILVA, F.F. e; FREATO, T.A. Avaliação de curvas de crescimento morfométrico de linhagens de tilápia do nilo (Oreochromis niloticus). Ciência e Agrotecnologia, v.31, p.1486-1492, 2007. DOI: 10.1590/ S1413-70542007000500032.

SARMENTO, J.L.R.; REZAZZI, A.J.; SOUZA, W.H. de; TORRES, R. de A.; BREDA, F.C.; MENEZES, G.R. de O. Estudo da curva de crescimento de ovinos Santa Inês. Revista Brasileira de Zootecnia, v.35, p.435-442, 2006. DOI: 10.1590/ S1516-35982006000200014.

SCOTT, D.E.; CASEY, E.D.; DONOVAN, M.F.; LYNCH, T.K. Amphibian lipid levels at metamorphosis correlate to post-metamorphic terrestrial survival. Oecologia, v.153, p.521-532, 2007. DOI: 10.1007/s00442-007-0755-6.

SECCO, E.M.; STÉFANI, M.V.; VIDOTTI, R.M. Apparent digestibility of different ingredients in diets for bullfrog Rana catesbiana tadpoles. Journal of the World Aquaculture Society, v.36, p.135-140, 2005. DOI: 10.1111/j.1749-7345.2005. tb00140.x.

SEIXAS FILHO, J.T. de; HIPOLITO, M.; CARVALHO, V. de F.; MARTINS, A.M.C.R.P. da F.; SILVA, L.N. da; CASTAGNA, A.A. Alterações histopatológicas em girinos de rã-touro alimentados com rações comerciais de diferentes níveis protéicos. Revista Brasileira de Zootecnia, v.37, p.2085-2089, 2008. DOI: 10.1590/ S1516-35982008001200002.

SEIXAS FILHO, J.T. de; NAVARRO, R.D.; PEREIRA, M.M.; MELLO, S.C.R.P.; LANNA, E.A.T.; LIMA, J.L.P. Desempenho zootécnico de girinos de rã-touro com diferentes níveis de proteína e energia digestíveis. Revista Brasileira de Saúde e Produção Animal, v.13, p.1112-1120, 2012. DOI: 10.1590/ S1519-99402012000400023.

SEIXAS FILHO, J.T. de; NAVARRO, R.D.; SILVA, L.N. da; GARCIA, S.L.R.; HIPOLITO, M. Desempenho de girinos de rã-touro alimentados com ração comercial contendo diferentes concentrações de proteína bruta. Revista Brasileira de Ciências Agrárias, v.5, p.428-433, 2010. DOI: 10.5039/agraria.v5i3a788.

SEIXAS FILHO, J.T. de; OLIVEIRA, M.G.A.; NAVARRO, R.D.; GARCIA, S.L.R.; MOURA, G. de S.; RIBEIRO FILHO, O.P. Atividades enzimáticas de girinos de rã-touro submetidos a rações com níveis de proteína. Archivos de Zootecnia, v.60, p.1161-1170, 2011. DOI: 10.4321/S0004-05922011000400031.

SILVA, D.J.; QUEIROZ, A.C. de. Análise de alimentos: métodos químicos e biológicos. 3.ed. Viçosa: Ed. UFV, 2002. 235p.

SILVA, F. de L.; ALENCAR, M.M. de; FREITAS, A.R. de; PACKER, I.U.; MOURÃO, G.B. Curvas de crescimento em vacas de corte de diferentes tipos biológicos. Pesquisa 
Agropecuária Brasileira, v.46, p.262-271, 2011. DOI: 10.1590/ S0100-204X2011000300006.

WILBUR, H.M. Complex life cycles. Annual Review of Ecology and Systematics, v.11, p.67-93, 1980. DOI: 10.1146/annurev. es.11.110180.000435.
WRIGHT, M.L.; RICHARDSON, S.E.; BIGOS, J.M. The fat body of bullfrog (Lithobates catesbeianus) tadpoles during metamorphosis: changes in mass, histology and melatonin content and effect of food deprivation. Comparative Biochemistry and Physiology, Part A, v.160, p.498-503, 2011. DOI: 10.1016/j. cbpa.2011.08.010.

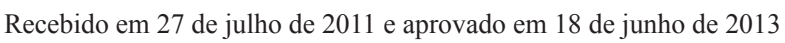

